\title{
Correlation of Left Ventricular Diastolic Function and Left Ventricular Geometry in Patients with Obstructive Sleep Apnoea Syndrome
}

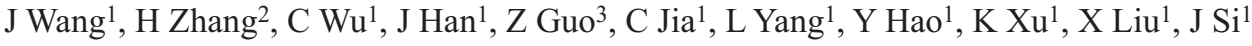

\begin{abstract}
Background: The aim of this study is to evaluate the correlation of the left ventricular diastolic function and the left ventricular geometry in patients with obstructive sleep apnoea syndrome (OSAS) by echocardiography.

Methods: The 181 patients diagnosed with OSAS were divided into the normal geometry group (NG), the concentric remodelling group (CR), the eccentric hypertrophy group (EH) and the concentric hypertrophy group $(\mathrm{CH})$. Pearson correlation analysis and multiple linear regression analysis were performed toward the correlation of the left ventricular diastolic function and the left ventricular geometry.

Results: The E peak in the EH and CH group was significantly reduced, with significant difference; the E/A, Em, Am and Em/Am was reduced in the order of the CR, EH and CH groups, while E/Em was increased, and the difference was significant. Pearson correlation analysis revealed that the Em/Am showed significant negative correlations with the left ventricular mass index (LVMI) $[r=-0.419]$ and relative wall thickness (RWT) $[r=-0.289]$, while the E/Em was significantly positively correlated with the LVMI $(r=$ $0.638)$ and $R W T[r=0.328](\mathrm{p}<0.001)$. Multiple linear regression analysis revealed that LVMI and $R W T$ had influence on the Em/Am and E/Em $\left(r_{2}=0.402, r_{2}=0.107, \mathrm{p}<0.001\right)$. The left ventricular diastolic dysfunction was the worst in the CH group.

Conclusions: There was correlation between the left ventricular diastolic dysfunction and the changes in cardiac geometry.
\end{abstract}

Keywords: Left ventricular remodelling, obstructive sleep apnoea syndrome, ultrasound

\section{Correlación de la Función Diastólica Ventricular Izquierda y Geometría Ventricular Izquierda en Pacientes con Síndrome de Apnea Obstructiva del Sueño}

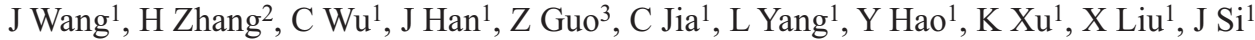

\begin{abstract}
RESUMEN
Antecedentes: El objetivo de este estudio fue evaluar la correlación de la función diastólica ventricular izquierda y de la geometría ventricular izquierda en pacientes con síndrome de apnea obstructiva del sueño (SAOS) mediante ecocardiografía.

Métodos: Los 181 pacientes diagnosticados con SAOS fueron divididos en los grupos siguientes: grupo de geometría normal $(G N)$, grupo de remodelación concéntrica $(R C)$, grupo de hipertrofia excéntrica (HE), y grupo de hipertrofia concéntrica (HC). Se realizaron análisis de correlación de Pearson y análisis de regresión lineal múltiple con respecto a la correlación de la función diastólica ventricular izquierda y de la geometría ventricular izquierda.

Resultados: El pico E en el grupo HE y HC se redujo significativamente, con diferencias significativas; el E/A, Em, Am y Em/Am se redujo en el orden de los grupos RC, HE y HC, mientras que E/Em fue aumentado, y la diferencia fue significativa. EL análisis de correlación de Pearson reveló que el Em/Am mostró correlaciones negativas significativas con el índice de masa ventricular izquierda (IMVI) $[r=-$ $0.419]$ y el grosor relativo de la pared (GRP) [ $r=-0.289]$, mientras que el E/Em se correlacionó significativamente de forma positiva con el IMVI $(r=0.638)$ y el GRP $[r=0.328](\mathrm{p}<0.001)$. El análisis
\end{abstract}

From: ${ }^{1}$ Department of Ultrasound, ${ }^{2}$ Department of Radiology and ${ }^{3}$ Department of Respiratory Medicine, The First Hospital of Shanxi Medical University, Taiyuan 030001, China.
Correspondence: Dr H Zhang, Department of Radiology, The First Hospital of Shanxi Medical University, No. 85 Jiefangnan Road, Nancheng District, Taiyuan 030001, China. Fax: +86 351 4639363; e-mail: huizhangoc@126.com. 
de regresión lineal múltiple reveló que IMVI y GRP tenían influencia sobre Em/Am y E/Em $\left(r_{2}=0.402\right.$, $\left.r_{2}=0.107, \mathrm{p}<0.001\right)$. La disfunción diastólica ventricular izquierda en el grupo HC fue la peor.

Conclusiones: Hubo una correlación entre la disfunción diastólica ventricular izquierda y los cambios en la geometría cardíaca.

Palabras claves: Remodelación ventricular izquierda, síndrome de apnea obstructiva del sueño, ultrasonido

West Indian Med J 2015; 64 (2): 93

\section{INTRODUCTION}

Obstructive sleep apnoea syndrome (OSAS) can cause a variety of cardiovascular diseases, and is an independent risk factor of morbidity and mortality in cardiovascular diseases (1). Because OSAS symptoms are nonspecific and the development of complications is occult and gradual, the original disease and the complications can progressively increase (2).

Left ventricular hypertrophy (LVH) is a common complication of OSAS $(3,4)$. Studies have shown that even without the potential cardiovascular disease, left ventricular systolic and diastolic dysfunction (LVSD and LVDD) and LVH were also associated with OSAS (5). The incidence of cardiovascular events was highest in concentric LVH (CLVH), middle level in eccentric LVH (ELVH) and concentric remodelling (CR), and lowest in normal geometry [NC] (6). The ELVH and CLVH were related to the LVSD and LVDD, respectively (7), and LVH was often associated with LVDD (8). Although studies have shown that the left ventricular ejection fraction (LVEF) of OSAS patients without other cardiovascular diseases was often in the normal range, diastolic dysfunction had already appeared, and could independently cause heart failure $(9,10)$, suggesting that the evaluation of LVDD in OSAS patients would be far more important than the evaluation of the systolic function. Accordingly, in the present study, the correlation of LVDD and left ventricular geometry in OSAS patients, as well as its influencing factors, was investigated.

\section{SUBJECTS AND METHODS}

From December 2010 to July 2012, patients were enrolled in the Department of Respiratory Disease Clinic in our hospital because of OSAS-suspected snoring. One hundred and eightyone patients were diagnosed as OSAS because polysomnography (PSG) monitoring revealed that the apnoea-hypopnoea index (AHI) was $>5$ times/hour and the conventional M-mode echocardiographic measurement revealed that LVEF was > $50 \%$. There were 153 males and 28 females, aged from 21 to 68 years old, with the mean age as $37( \pm 18.4)$ years. The patients were informed and consented to the timed monitoring of the night and daytime blood pressures, echocardiography and blood biochemical examinations. The patients had no myocardial infarction, atrial fibrillation, moderate or severe valvular regurgitation or stenosis, chronic kidney disease, chronic obstructive pulmonary disease, systemic lupus erythematosus or other diseases, and were not night-shift workers. Among the patients, hypertension was identified as systolic blood pressure $\geq 140 \mathrm{mmHg}$ and/or diastolic blood pressure $\geq 90 \mathrm{mmHg}$, or have been diagnosed and was taking antihypertensive drugs; obesity was identified as body mass index (BMI) $\geq 30 \mathrm{~kg} / \mathrm{m}^{2}$. This study was conducted in accordance with the Declaration of Helsinki and with approval from the Ethics Committee of Shanxi Medical University. Written informed consent was obtained from all participants.

The Bond EmblaN-7000 (Medcare Flaga, Reykjavik, Iceland) and PolyproYH2000 (BMC Medical Co, Ltd, Beijing, China) polysomnography monitoring analyser were used to perform the more than seven hours overnight PSG monitoring of all the subjects, and blood glucose and blood lipid were investigated the next morning. Twenty-four hours before the monitoring, sleeping pills, alcohol, tea and coffee were prohibited. The AHI, the lowest night time arterial oxygen saturation $\left(\mathrm{SaO}_{2}\right)$, the night time mean $\mathrm{SaO}_{2}$, the T90 (percentage of the $\mathrm{SaO}_{2}<90 \%$ sleep time in the total sleep time) and the oxygen desaturation index (ODI) were recorded; AHI $\geq 5$ times/hour was diagnosed as OSAS (11).

The My Lab 90-type colour Doppler ultrasound (Esaote SpA, Genoa, Italy) was used the next morning, with PA 230 probe (Esaote SpA, Genoa, Italy), and the frequency was $1.5 \sim 4.0 \mathrm{MHz}$. After calmly resting for at least 30 minutes, the patient was placed in the left lateral decubitus position and connected to the electrocardiogram (ECG) for the parasternal longaxis view, the short-axis view, the apical two-chamber cross-sectional view and the apical four-chamber cross-sectional view. The parameter measurement should be performed for at least three cardiac cycles, and all the echocardiographic examinations were performed by the same experienced ultrasound expert.

According to the criteria of the American Society of Echocardiography (12), the M-mode echocardiography was performed on the parasternal left ventricular long axis section to detect the left ventricular diastolic dimension (LVDd), left ventricular systolic dimension (LVDs), posterior wall thickness (PWT) and interventricular septal thickness (IVST). The left ventricular shortening fraction (LVSF) and LVEF were used to assess left ventricular systolic function (13); normal left ventricular systolic function should be LVSF $\geq 28 \%$ and LVEF $\geq 50 \%$. The left ventricular mass (LVM) was calculated (14): $\mathrm{LVM}=1.04 \times\left[(\mathrm{LVDd}+\mathrm{PWT}+\mathrm{IVST})^{3}-\mathrm{LVDd}^{3}\right]-13.6$; left ventricular mass index $(\mathrm{LVMI})=\mathrm{LVM} /$ height $^{2.7}(14)$ and relative wall thickness $($ RWT $)=($ IVST + PWT $) /$ LVDd $(15)$. According to LVMI $>46.7 \mathrm{~g} / \mathrm{m}^{2.7}$ (female) or $49.2 \mathrm{~g} / \mathrm{m}^{2.7}$ (male), RWT $>0.42(14,16)$, the left ventricular geometry was divided into: normal geometry (NG) - the LVMI was normal, 
and the RWT was $<0.42$; concentric remodelling $(\mathrm{CR})-$ the LVMI was normal, and the RWT was $\geq 0.42$; eccentric hypertrophy (EH): the LVMI increased, and the RWT was < 0.42; concentric hypertrophy $(\mathrm{CH})$ : the LVMI increased, and the RWT was $\geq 0.42$.

According to the requirements of the American Society of Echocardiography (17), when in the apical four-chamber view, the pulse Doppler sampling volume was placed between the anterior and posterior lobes of the mitral valve to record the diastolic mitral blood flow spectrum: the early diastolic peak velocity (E-wave), the atrial contraction peak velocity (A-wave), the isovolumic relaxation time (IVRT) and the mitral E-wave deceleration time (DT). For the pulmonary venous blood flow spectrum, the pulse Doppler sampling volume was placed at $1-2 \mathrm{~cm}$ in the pulmonary vein to measure the systolic peak velocity ( $\mathrm{S}$-wave), the diastolic peak velocity (D-wave) and the backwards blood flow wave velocity in atrial contraction (PVa). For Doppler tissue detection, the $2 \mathrm{~mm}$ sampling volume was placed in the interventricular septum of the mitral ring to measure the early diastolic velocity (Em) and the late diastolic velocity (Am) for the calculation of the E/Em ratio. The colour Doppler of the apical four-chamber view showed the left ventricular diastolic flow beam, adjusted the M-type sampling line to be parallel with the flow beam, and exhibited the M-mode colour Doppler image through the centre of the flow beam (the aliasing limit was $40 \sim 50 \mathrm{~cm} / \mathrm{s}$ ), and the linear segment slope at the red- or blue-transformation of the early diastolic coloured blood beam was the left ventricular early diastolic velocity of propagation ( $\mathrm{Vp})$.

\section{Statistical analysis}

The SPSS 13.0 software was used for statistical analysis. The normally distributed continuous variables are expressed as $\bar{x} \pm \mathrm{s}$; the classification variables are expressed as the percentage. The comparison of each mean indicator of each group used analysis of variance (ANOVA). If the difference was statistically significant, the least significant difference (LSD) method would be used for the further intergroup pairwise comparison. The correlation coefficient assessment of the left ventricular diastolic function parameters with LVMI and RWT used the Pearson correlation analysis. The multiple linear regression analysis was used to analyse the left ventricular diastolic function parameters which impacted LVMI and RWT. A $p$-value $<0.05$ considered statistically significant.

\section{RESULTS}

In this study, a total of 181 OSAS patients was enrolled, and the left ventricular remodelling types were: 71 cases of $\mathrm{NG}$ (39.2\%), 40 cases of CR (22.1\%), 34 cases of EH (18.8\%) and 36 cases of $\mathrm{CH}(19.9 \%)$. Among the $\mathrm{NG}, \mathrm{CR}, \mathrm{EH}$ and $\mathrm{CH}$ group, the AHI, T90 and ODI increased progressively, while the lowest $\mathrm{SaO}_{2}$ and the mean $\mathrm{SaO}_{2}$ declined progressively, but the difference was not statistically significant $(p>0.05)$. Body mass index and obesity were higher in the EH group, but

Table 1: Comparison of clinical data and polysomnography in obstructive sleep apnoea syndrome patients with four kinds of left ventricular geometry $(\bar{x} \pm s)$

\begin{tabular}{|c|c|c|c|c|}
\hline & NG $(n=71)$ & $C R(n=40)$ & EH $(n=34)$ & $\mathrm{CH}(\mathrm{n}=36)$ \\
\hline m (\%) & 84.50 & 90.00 & 82.40 & 80.60 \\
\hline Age (years) & $42.39 \pm 11.27$ & $44.90 \pm 8.51$ & $47.38 \pm 11.77$ & $50.50 \pm 10.96$ \\
\hline BMI $\left(\mathrm{kg} / \mathrm{m}^{2}\right)$ & $27.16 \pm 3.13$ & $27.33 \pm 3.96$ & $28.88 \pm 3.31$ & $28.25 \pm 4.51$ \\
\hline Neck circumference $(\mathrm{cm})$ & $39.61 \pm 4.40$ & $39.27 \pm 4.18$ & $40.75 \pm 3.85$ & $39.76 \pm 3.88$ \\
\hline Waist circumference $(\mathrm{cm})$ & $97.56 \pm 9.63$ & $97.26 \pm 7.93$ & $98.75 \pm 10.60$ & $100.09 \pm 10.82$ \\
\hline Hip circumference $(\mathrm{cm})$ & $103.84 \pm 6.69$ & $103.65 \pm 6.79$ & $108.86 \pm 14.08$ & $105.91 \pm 7.74$ \\
\hline Smoking (\%) & 42.86 & 60.00 & 44.12 & 47.22 \\
\hline Obesity (\%) & 46.48 & 40.00 & 76.47 & 50.00 \\
\hline Hypertension (\%) & 49.44 & 48.50 & 47.06 & 46.44 \\
\hline $\mathrm{FG}(\mathrm{mmol} / \mathrm{L})$ & $5.75 \pm 1.11$ & $5.71 \pm 1.22$ & $6.00 \pm 1.81$ & $5.71 \pm 1.15$ \\
\hline $\mathrm{TC}(\mathrm{mmol} / \mathrm{L})$ & $4.73 \pm 0.94$ & $4.73 \pm 0.98$ & $4.62 \pm 0.96$ & $4.44 \pm 0.93$ \\
\hline TG (mmol/L) & $1.99 \pm 1.00$ & $2.12 \pm 1.26$ & $2.02 \pm 0.90$ & $2.55 \pm 1.70$ \\
\hline HDL (mmol/L) & $1.13 \pm 0.22$ & $1.09 \pm 0.23$ & $1.11 \pm 0.27$ & $1.14 \pm 0.29$ \\
\hline $\mathrm{LDL}(\mathrm{mmol} / \mathrm{L})$ & $2.66 \pm 0.63$ & $2.60 \pm 0.91$ & $2.77 \pm 0.84$ & $2.40 \pm 0.75$ \\
\hline dSBP (mmHg) & $129.00 \pm 13.22$ & $127.55 \pm 12.39$ & $128.77 \pm 13.23$ & $130.13 \pm 14.08$ \\
\hline dDBP (mmHg) & $86.30 \pm 8.31$ & $83.88 \pm 10.32$ & $85.12 \pm 8.83$ & $86.96 \pm 8.54$ \\
\hline nSBP (mmHg) & $126.83 \pm 12.30$ & $126.19 \pm 14.55$ & $129.15 \pm 14.96$ & $130.35 \pm 19.64$ \\
\hline nDBP (mmHg) & $85.02 \pm 10.07$ & $83.71 \pm 10.98$ & $82.93 \pm 11.19$ & $86.27 \pm 12.35$ \\
\hline $\mathrm{AHI}(/ \mathrm{h})$ & $46.60 \pm 27.35$ & $47.63 \pm 31.23$ & $49.37 \pm 28.57$ & $51.67 \pm 34.09$ \\
\hline Lowest $\mathrm{SaO}_{2}(\%)$ & $64.01 \pm 17.88$ & $62.88 \pm 16.26$ & $60.62 \pm 19.42$ & $59.39 \pm 22.32$ \\
\hline Mean $\mathrm{SaO}_{2}(\%)$ & $91.00 \pm 4.08$ & $90.63 \pm 4.54$ & $87.86 \pm 9.31$ & $86.74 \pm 7.42$ \\
\hline T90 (\%) & $30.00 \pm 21.11$ & $30.50 \pm 19.36$ & $31.64 \pm 31.55$ & $33.18 \pm 30.14$ \\
\hline ODI $(\%)$ & $49.66 \pm 31.24$ & $51.82 \pm 35.41$ & $52.68 \pm 31.07$ & $53.02 \pm 38.44$ \\
\hline Heart rate (beats/min) & $73.84 \pm 9.08$ & $74.17 \pm 10.47$ & $71.09 \pm 8.30$ & $75.85 \pm 20.39$ \\
\hline
\end{tabular}

Compared with the NG group, ${ }^{*} p<0.05$; compared with the CR group, ${ }^{\sharp} p<0.05$; compared with EH group, ${ }^{\Delta} p<0.05$. BMI: body mass index; FG: fasting plasma glucose; TC: total cholesterol; TG: triglycerides; HDL: high-density lipoprotein; LDL: low-density lipoprotein; SBP: systolic blood pressure; DBP: diastolic blood pressure; d: day; n: nocturnal AHI: apnoea-hypopnoea index; $\mathrm{SaO}_{2}$ : oxygen saturation; T90: percentage of $\mathrm{SaO}_{2}$ less than $90 \%$; ODI: oxygen dissociation index 
there was no statistically significant difference when compared with the other three groups $(p>0.05)$. There was no statistical significance in gender, age, heart rate, blood pressure, neck circumference, waist circumference, hip circumference, smoking history, total cholesterol (TC), triglycerides (TG), highdensity lipoprotein (HDL), low-density lipoprotein (LDL) and fasting glucose in the intergroup comparison $[p>0.05]$ (Table $1)$.

\section{Echocardiographic left ventricular diastolic function parameters}

For the left ventricular diastolic function parameters in OSAS patients, the E peak was significantly reduced in the $\mathrm{EH}$ and $\mathrm{CH}$ group, with significant intergroup difference. Compared with the NG group, the E/A gradually decreased in the CR, EH and $\mathrm{CH}$ group, and the difference was significant. The difference between the $\mathrm{EH}$ and $\mathrm{CH}$ group was significant. The Em, Am and Em/Am gradually reduced in the $\mathrm{CR}, \mathrm{EH}$ and $\mathrm{CH}$ groups, and the intergroup difference was significant. The $\mathrm{E} / \mathrm{Em}$ were increased in turn, and there was significant difference between the $\mathrm{EH}, \mathrm{CH}$ groups and the NG, CR groups; the difference between the $\mathrm{EH}$ and $\mathrm{CH}$ group was significant. The A, DT, IVRT, S, D, PVa and Vp had no significant intergroup difference (Table 2).

\section{Pearson correlation coefficient}

The correlation coefficient is the relationship between the left ventricular diastolic function parameters (as the independent variables) and the LVMI and RWT (as the independent variables after adjusting for risk factors: age, gender, blood pressure and heart rate). The Pearson correlation analysis demonstrated that the Em/Am had a significant negative correlation with LVMI $(p<0.001)$ and RWT $(p<0.001)$, while E/Em was positively related to LVMI $(p<0.001)$ and RWT $(p$ $<0.001$; Table 3).

Table 3: Pearson correlation coefficient between LVMI, RWT and the left ventricular diastolic function parameters

\begin{tabular}{lrrrr}
\hline & \multicolumn{2}{c}{ RWT } & \multicolumn{2}{c}{ LVMI } \\
& $\boldsymbol{r}$ & $\boldsymbol{p}$ & $\boldsymbol{r}$ & $\boldsymbol{p}$ \\
\hline MV E peak & -0.032 & 0.327 & -0.090 & 0.270 \\
MV A peak & 0.004 & 0.200 & 0.019 & 0.118 \\
MV E/A & -0.118 & 0.150 & -0.014 & 0.880 \\
DT (ms) & 0.024 & 0.763 & -0.059 & 0.438 \\
IVRT (ms) & -0.022 & 0.810 & 0.078 & 0.321 \\
Em (cm/s) & 0.016 & 0.264 & 0.078 & 0.335 \\
Am (cm/s) & 0.041 & 0.117 & 0.032 & 0.113 \\
Em/Am & -0.289 & $<0.001^{*}$ & -0.419 & $<0.001^{*}$ \\
E/Em & 0.328 & $<0.001^{*}$ & 0.634 & $<0.001^{*}$ \\
S (cm/s) & -0.028 & 0.822 & -0.030 & 0.216 \\
D (cm/s) & -0.126 & 0.313 & 0.045 & 0.553 \\
S/D & 0.019 & 0.406 & -0.058 & 0.061 \\
PVa (cm/s) & 0.046 & 0.771 & -0.016 & 0.782 \\
Vp (cm/s) & 0.054 & 0.626 & 0.012 & 0.413 \\
\hline
\end{tabular}

RWT: relative wall thickness; LVMI: left ventricular mass index; E peak: left ventricular early diastolic peak velocity; A peak: left ventricular late diastolic peak velocity; DT: E peak deceleration time; IVRT: left ventricular isovolumic relaxation time; the Doppler tissue blood flow spectrum of the interventricular septum of the mitral ring; Em: early diastolic peak velocity; Am: late diastolic peak velocity; the blood flow spectrum of the pulmonary vein: S-wave: ventricular contraction wave peak, D-wave: ventricular diastolic wave peak; PVa: the backwards blood flow wave velocity in atrial contraction; Vp: left ventricular early diastolic flow velocity of propagation

Table 2: Comparison of the echocardiographic diastolic function parameters in obstructive sleep apnoea syndrome patients with four kinds of left ventricular geometry $(\bar{x} \pm \mathrm{s})$

\begin{tabular}{lcccc}
\hline & NG $(\mathbf{n}=\mathbf{7 1})$ & $\mathbf{C R}(\mathbf{n}=\mathbf{4 0})$ & $\mathbf{E H}(\mathbf{n}=\mathbf{3 4})$ & $\mathbf{C H}(\mathbf{n}=\mathbf{3 6})$ \\
\hline MV E peak $(\mathrm{cm} / \mathrm{s})$ & $78.00 \pm 14.11$ & $76.12 \pm 17.34$ & $75.11 \pm 18.10^{\Delta}$ & $55.14 \pm 13.12^{* \Delta}$ \\
MV A peak $(\mathrm{cm} / \mathrm{s})$ & $68.36 \pm 16.36$ & $76.52 \pm 17.40$ & $76.75 \pm 21.57$ & $73.88 \pm 20.94$ \\
MV E/A & $1.01 \pm 0.29$ & $0.97 \pm 0.18^{*}$ & $0.97 \pm 0.15^{*}$ & $0.74 \pm 0.24^{* \Delta}$ \\
DT $(\mathrm{ms})$ & $120.50 \pm 51.90$ & $123.84 \pm 59.84$ & $138.31 \pm 44.52$ & $167.13 \pm 44.52$ \\
IVRT $(\mathrm{ms})$ & $100.28 \pm 25.89$ & $107.55 \pm 20.81$ & $99.00 \pm 22.06$ & $114.94 \pm 24.32$ \\
Em $(\mathrm{cm} / \mathrm{s})$ & $13.51 \pm 1.44$ & $10.20 \pm 0.92^{*}$ & $8.32 \pm 1.27^{* \#}$ & $6.15 \pm 1.07^{* \# \Delta}$ \\
Am $(\mathrm{cm} / \mathrm{s})$ & $10.46 \pm 1.27$ & $10.87 \pm 1.22^{*}$ & $9.90 \pm 0.91^{* \#}$ & $8.41 \pm 0.82^{* \# \Delta}$ \\
Em/Am & $1.29 \pm 0.13$ & $0.95 \pm 0.15^{*}$ & $0.83 \pm 0.10^{* \#}$ & $0.73 \pm 0.12^{* * \Delta}$ \\
E/Em & $7.78 \pm 0.81$ & $7.23 \pm 1.27$ & $9.09 \pm 1.78^{* \#}$ & $12.35 \pm 2.41^{* \# \Delta}$ \\
S $(\mathrm{cm} / \mathrm{s})$ & $50.67 \pm 9.30$ & $54.05 \pm 11.69$ & $51.45 \pm 10.99$ & $54.69 \pm 8.63$ \\
D $(\mathrm{cm} / \mathrm{s})$ & $37.00 \pm 8.06$ & $34.87 \pm 5.25$ & $36.88 \pm 16.72$ & $38.68 \pm 9.46$ \\
S/D & $1.42 \pm 0.35$ & $1.67 \pm 0.45$ & $1.53 \pm 0.25$ & $1.48 \pm 0.36$ \\
PVa $(\mathrm{cm} / \mathrm{s})$ & $25.10 \pm 4.02$ & $28.80 \pm 5.12$ & $30.30 \pm 4.10$ & $30.60 \pm 6.15$ \\
Vp $(\mathrm{cm} / \mathrm{s})$ & $62.25 \pm 4.02$ & $60.14 \pm 5.12$ & $58.02 \pm 4.10$ & $57.00 \pm 6.15$ \\
\hline
\end{tabular}

Compared with the NG group, ${ }^{*} p<0.05$; compared with the CR group, ${ }^{*} p<0.05$; compared with EH group, ${ }^{\Delta} p<0.05$. E peak: left ventricular early diastolic peak velocity; A peak: left ventricular late diastolic peak velocity; DT: E peak deceleration time; IVRT: left ventricular isovolumic relaxation time; the Doppler tissue blood flow spectrum of the interventricular septum of the mitral ring; Em: early diastolic peak velocity; Am: late diastolic peak velocity; the blood flow spectrum of the right upper pulmonary vein: S-wave: ventricular contraction wave peak; D-wave: ventricular diastolic wave peak; PVa: the backwards blood flow wave velocity in atrial contraction; Vp: left ventricular early diastolic flow velocity of propagation 


\section{Multiple linear regression analysis}

The multiple linear regression analysis showed that Em/Am and E/Em had influence toward the LVMI and RWT $\left[\mathrm{r}^{2}=0.17\right.$, $\left.\mathrm{r}^{2}=0.21, p<0.001\right]$ (Tables 4, 5).

Table 4: Multiple linear regression analysis between LVMI and the left ventricular diastolic function parameters $\mathrm{Em} / \mathrm{Am}$ and $\mathrm{E} / \mathrm{Em}$

\begin{tabular}{lccccc}
\hline LVMI & $\boldsymbol{r}=\mathbf{0 . 6 3 4}$ & $\boldsymbol{r}^{2}=\mathbf{0 . 4 0 2}$ & Adjusted & $\begin{array}{c}\boldsymbol{r}^{2} \text { change }= \\
\mathbf{0 . 3 9 9}\end{array}$ & $\boldsymbol{p}<\mathbf{0 . 0 0 1}^{*}$ \\
\hline Coefficient & $\beta$ & $S E$ & standard & $\beta$ & $t$ \\
Em/Am & -6.204 & 2.443 & -0.171 & -2.540 & $p<0.001^{*}$ \\
E/Em & 2.979 & 0.359 & 0.559 & 8.303 & $p<0.001^{*}$ \\
\end{tabular}

LVMI: left ventricular mass index; Em: early diastolic peak velocity; Am: late diastolic peak velocity; E: left ventricular early diastolic peak velocity

Table 5: Multiple linear regression analysis between RWT and the left ventricular diastolic function parameters $\mathrm{Em} / \mathrm{Am}$ and $\mathrm{E} / \mathrm{Em}$

\begin{tabular}{lccccc}
\hline RWT & $\boldsymbol{r}=\mathbf{0 . 3 2 8}$ & $\boldsymbol{r}^{2}=\mathbf{0 . 1 0 7}$ & Adjusted & $\begin{array}{c}\boldsymbol{r}^{2} \text { change }= \\
\mathbf{0 . 1 0 1}\end{array}$ & $\boldsymbol{p}<\mathbf{0 . 0 0 1}^{*}$ \\
\hline Coefficient & $\beta$ & $S E$ & standard & $\beta$ & $t$ \\
Em/Am & -0.034 & 0.015 & -0.190 & -2.274 & $p<0.001^{*}$ \\
E/Em & 0.070 & 0.020 & -0.253 & 3.030 & $p<0.001^{*}$ \\
\hline
\end{tabular}

RWT: relative wall thickness; Em: early diastolic peak velocity; Am: late diastolic peak velocity; E: left ventricular early diastolic peak velocity.

\section{DISCUSSION}

In this study, echocardiographic technology was used to evaluate the relevance and the influencing factors between left ventricular diastolic function and left ventricular geometry in OSAS patients. Our results showed that OSAS could lead to ventricular remodelling. Approximately $60.8 \%$ of the OSAS patients had abnormal left ventricular geometry and OSAS patients with left ventricular remodelling would suffer from LVDD, among which the $\mathrm{CH}$ group exhibited the most dysfunction. Left ventricular diastolic dysfunction was correlated with the changes of cardiac abnormal geometry.

Epidemiological studies (2) have shown that OSAS patients often have cardiovascular risk factors such as hypertension, hyperlipidaemia and obesity; half (51.4\%) of these patients tend to have hypertension. Kim et al (18) divided 42 OSAS patients into two groups according to OSAS severity, namely, the mild to moderate group $(n=18)$ and the severe group $(n=24)$. Together with 20 cases of non-OSAS patients, the results showed that there was no significant difference in the age, BMI, heart rate, obesity, systolic blood pressure, diastolic blood pressure, fasting glucose and total cholesterol in the three groups. In this study, the majority of OSAS patients were young, with an average age of $37 \pm 8.4$ years old; about $50 \%$ suffered from obesity, $57.6 \%$ suffered from hyperlipidaemia and $47.5 \%$ suffered from hypertension. According to the left ventricular geometric grouping, the results showed that there was no significant difference in gender, age, heart rate, blood pressure, neck circumference, waist circumference, hip circumference, smoking history, TC, TG, HDL, LDL and fasting blood sugar.

Obstructive sleep apnoea syndrome is a complex chronic respiratory disease. The severity of OSAS, as well as the complications, such as obesity, hypertension and abnormal lipid metabolism, would affect the left ventricular geometry in OSAS patients. Myslinski et al (3) performed echocardiography on 70 OSAS patients who were treated for hypertension at the same time; the results showed that $63 \%$ of patients had EH and CH. Cioffi et al (4) studied 137 cases of middle-aged OSAS patients, and the study showed that the rates of NG, CR, $\mathrm{EH}$ and $\mathrm{CH}$ in 51 mild OSAS patients were 53\%, 4\%, 35\% and $8 \%$, respectively; among the 86 mild-severe OSAS patients, the above rates were $27 \%, 24 \%, 15 \%$ and $34 \%$, respectively. Our results showed that OSAS could lead to left ventricular remodelling: 71 cases were of $\mathrm{NG}(39.2 \%), 40$ cases were of CR (22.1\%), 34 cases were of EH (18.8\%) and 36 cases were of $\mathrm{CH}(19.9 \%)$. The above results were not exactly the same, which might be correlated with the race, OSAS severity and disease duration, whether associated with hypertension or being given decompression or continuous positive airway pressure (CPAP) therapy, and the patient's socio-economic status, etc.

Ventricular diastolic function is the comprehensive reflection of the ventricular anterior and posterior load, heart rate, myocardial contractility, myocardial relaxation and myocardial stiffness degree, which would be affected by many factors such as age, breathing, heart rate, sampling volume, load status, blood flow, orifice area, velocity and angle, atrial pressure and ventricular pressure (19).

Usui et al (8) reported that OSAS would not only lead to left ventricular hypertrophy, but also result in LVDD. Therefore, we grouped the OSAS patients according to the left ventricular geometric patterns, and observed in LVDD. The results showed that among the abnormal geometry groups (CR, EH and $\mathrm{CH}$ ), the left ventricular diastolic function parameters, namely E peak, E/A, Em, Am and Em/Am, were reduced, while E/Em increased, suggesting that the OSAS left ventricular remodelling patients suffered from LVDD, and the $\mathrm{CH}$ group exhibited the heaviest extent of the damage; secondly, Doppler tissue technology was sensitive in detecting the left ventricular diastolic function. Doppler tissue imaging (DTI) could be a new means in evaluating ventricular diastolic function, and would be affected by the heart rate and cardiac stress (20).

In the study by Kim et al (18), only the Em in the group with severe OSAS significantly decreased, suggesting that LVDD in severe OSAS was much more severe. Akar Bayram et al (5) used DTI to evaluate the left ventricular systolic and diastolic functions of 28 newly-diagnosed moderate and severe OSAS patients, and followed up to investigate the efficacy of six-month CPAP on left ventricular systolic and diastolic functions. The results showed that compared with the control group, the left ventricular diastolic function parameters (Em and Em/Am) of the OSAS patients were significantly 
reduced; after the treatment, the above parameters were significantly higher, suggesting that OSAS would result in the patients with LVDD, while the CPAP treatment could improve left ventricular diastolic function. Haruki et al (9) conducted echocardiography on 29 OSAS patients, and found that, compared with the control group, the left ventricular diastolic function parameter (E/A) was significantly reduced, suggesting that OSAS patients suffered from diastolic dysfunction.

In this study, the Pearson correlation and multiple linear regression analysis showed that left ventricular diastolic function parameters, namely Em/Am and E/Em, were correlated with LVMI and RWT, suggesting that LVDD was related to cardiac geometric changes. Usui et al (10) analysed the correlation between left ventricular diastolic function parameters and left ventricular geometry of OSAS patients with the single factor linear regression analysis; the results showed that E/A was negatively correlated with LVMI and RWT. Kim et al (18) studied the influencing factors of OSAS on LVDD, and the univariate linear regression analysis showed that Em was negatively correlated with LVMI.

When the OSAS patients exhibited apnoea, the intrathoracic pressure would intensely fluctuate, the long-term effects would result in gradual hypertrophy in the myocardial cells and the ventricular wall thickness would increase. The body would enhance respiratory inspiration to fight the closure of the upper airway in OSAS, causing the further decline of the negative intrathoracic pressure, thereby affecting the intrathoracic haemodynamic performance, which normally appears as increasing transmembrane pressure and left ventricular afterload, thus impacting the left ventricular filling. When the breathing is restored, the increased venous return would enable the expansion of the right ventricle, the interventricular septum would then shift to the left, so that the left ventricular compliance and the left ventricular diastolic filling would decrease. The long-term changes of the load and capacity, as well as the ventricular wall thickening in the latter period would eventually cause structural and functional changes of the ventricle $(19,21)$. Ventricular hypertrophy is largely caused by the larger ventricular cells, and would also increase the myofilament density of ventricular cells. The ventricular cells resting tension then increases, finally resulting in the enhancement of the ventricular cells' stiffness; the ventricular cells' compliance decreases, causing diastolic dysfunction because of the heart failure. Covell and Ross (22) emphasized that the geometric changes were caused by myocardial hypertrophy, the different geometry of ventricular hypertrophy, interstitial fibrosis, myocardial contractility and the combined changes among the cardiac cells, which might all lead to damage of the diastolic function.

This study has some limitations. Firstly, there might be some OSAS patients who had previously been diagnosed as OSAS, but did not receive the treatment, while the OSAS duration and severity would affect the distribution of left ventricular geometry and the changes of left ventricular diastolic function. Secondly, only a small percentage of patients in our study was females, so the results could not be generalized to women under the same general conditions. Thirdly, in the assessment of the diastolic function in all the patients, because the image quality was unsatisfactory, the standard pulmonary vein outflow velocity model and left ventricular M-colour flow beam could not be obtained.

\section{REFERENCES}

1. Mannarino MR, Di Filippo F, Pirro M. Obstructive sleep apnea syndrome. Eur J Intern Med 2012; 3: 586-93.

2. Mirrakhimov AE, Sooronbaev T, Mirrakhimov EM. Prevalence of obstructive sleep apnea in Asian adults: a systematic review of the literature. BMC Pulm Med 2013; 13: 10.

3. Myslinski W, Duchna HW, Rasche K, Dichmann M, Mosiewicz J, Schultze-Werninghaus G. Left ventricular geometry in patients with obstructive sleep apnea coexisting with treated systemic hypertension. Respiration 2007; 74: 176-83.

4. Cioffi G, Russo TE, Stefenelli C, Selmi A, Furlanello F, Cramariuc D et al. Severe obstructive sleep apnea elicits concentric left ventricular geometry. J Hypertens 2010; 28: 1074-82.

5. Akar Bayram N, Ciftci B, Durmaz T, Keles T, Yeter E, Akcay M et al. Effects of continuous positive airway pressure therapy on left ventricular function assessed by tissue Doppler imaging in patients with obstructive sleep apnoea syndrome. Eur J Echocardiogr 2009; 10: 376-82.

6. Adamu UG, Kolo PM, Katibi IA, Opadijo GO, Omotosho AB, Araoye MA. Relationship between left ventricular diastolic function and geometric patterns in Nigerians with newly diagnosed systemic hypertension. Cardiovasc J Afr 2009; 20: 173-7.

7. Fox ER, Taylor J, Taylor H, Han H, Samdarshi T, Arnett D et al. Left ventricular geometric patterns in the Jackson cohort of the Atherosclerotic Risk in Communities (ARIC) Study: clinical correlates and influences on systolic and diastolic dysfunction. Am Heart J 2007; 153: 238-44.

8. Usui Y, Takata Y, Inoue Y, Shimada K, Tomiyama H, Nishihata Y et al. Coexistence of obstructive sleep apnea and metabolic syndrome is independently associated with left ventricular hypertrophy and diastolic dysfunction. Sleep Breath 2012; 16: 677-84.

9. Haruki N, Takeuchi M, Nakai H, Kanazawa Y, Tsubota N, Shintome R et al. Overnight sleeping induced daily repetitive left ventricular systolic and diastolic dysfunction in obstructive sleep apnea: quantitative assessment using tissue Doppler imaging. Eur J Echocardiogr 2009; 10: 769-75.

10. Usui Y, Takata Y, Inoue Y, Tomiyama H, Kurohane S, Hashimura Y et al. Severe obstructive sleep apnea impairs left ventricular diastolic function in non-obese men. Sleep Med 2013; 14: 155-9.

11. Park JG, Ramar K, Olson EJ. Updates on definition, consequences, and management of obstructive sleep apnea. Mayo Clin Proc 2011; 86: 549-54.

12. Sahn DJ, DeMaria A, Kisslo J, Weyman AL. Recommendations regarding quantitation in M-mode echocardiography: results of a survey of echocardiographic measurements. Circulation 1978; 58: 1072-83.

13. Quinones MA, Waggoner AD, Reduto LA, Nelson JG, Young JB, Winters WL Jr et al. A new, simplified and accurate method for determining ejection fraction with two-dimensional echocardiography. Circulation 1981; 64: 744-53.

14. Verdecchia P, Schillaci G, Borgioni C, Ciucci A, Battistelli M, Bartoccini $\mathrm{C}$ et al. Adverse prognostic significance of concentric remodeling of the left ventricle in hypertensive patients with normal left ventricular mass. J Am Coll Cardiol 1995; 25: 871-8.

15. Foppa M, Duncan BB, Rohde L. Echocardiography-based left ventricular mass estimation: how should we define hypertrophy? Cardiovasc U1trasound 2005; 3: 17.

16. Ganau A, Devereux RB, Roman MJ, de Simone G, Pickering TG, Saba PS et al. Patterns of left ventricular hypertrophy and geometric remodeling in essential hypertension. J Am Coll Cardiol 1992; 19: 1550-8. 
17. Oh JK, Appleton CP, Hatle LK, Nishimura RA, Seward JB, Tajik AJ. The noninvasive assessment of left ventricular diastolic function with two dimensional and Doppler echocardiography. J Am Soc Echocardiogr 1997; 10: $246-70$.

18. Kim SH, Cho GY, Shin C, Lim HE, Kim YH, Song WH et al. Impact of obstructive sleep apnea on left ventricular diastolic function. Am J Cardiol 2008; 101: 1663-8.

19. Baguet JP, Barone-Rochette G, Tamisier R, Levy P, Pépin JL. Mechanisms of cardiac dysfunction in obstructive sleep apnea. Nat Rev Cardiol 2012; 9: 679-88.
20. Nagueh SF, Appleton CP, Gillebert TC, Marino PN, Oh JK, Smiseth OA et al. Recommendations for the evaluation of left ventricular diastolic function by echocardiography. Eur J Echocardiogr 2009; 10: 165-93.

21. Vrints H, Shivalkar B, Hilde H, Vanderveken OM, Hamans E, Van de Heyning $\mathrm{P}$ et al. Cardiovascular mechanisms and consequences of obstructive sleep apnoea. Acta Clin Belg 2013; 68: 169-78.

22. Covell JW, Ross J. Systolic and diastolic function (mechanics) of the intact heart. Comprehensive Physiology 2011; (Suppl 6): 741-85. 